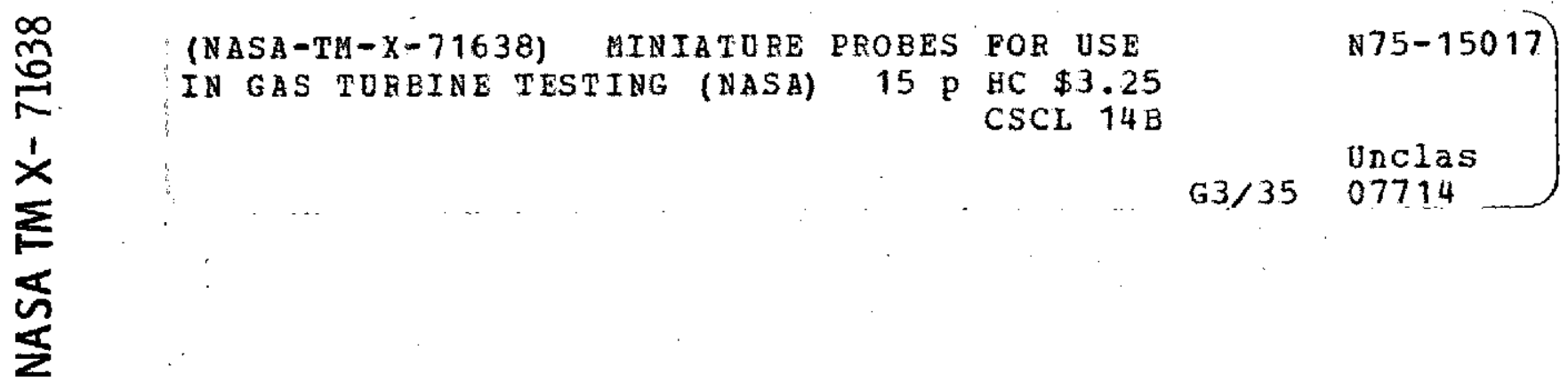

\title{
MINIATURE PROBES FOR USE IN GAS TURBINE TESTING
}

by George E, Glawe and Lloyd N. Krause Lewis Research Center

Cleveland, Ohio 44135

TECHNICAL PAPER to be presented at Automative Engineering Conference sponsored

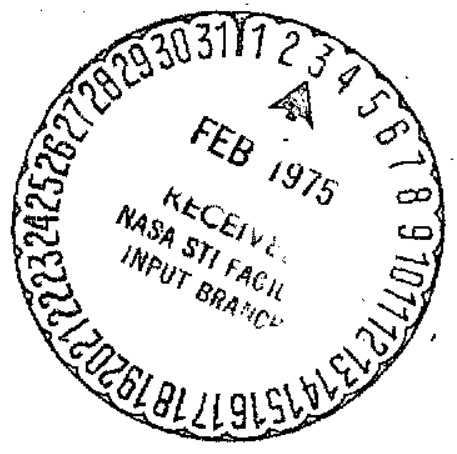
by the Society of Automative Engineers Detroit, Michigan, February 24-28, 1974 


\section{ABSTRACT}

Because of space limitations and system complexity in many applications assoclated with gas turbine testing, extremely small flow measuring probes have sometimes been required. This paper presents several examples of these minlature probes (null type as well as fixed position) which have proved useful in aircraft and space power systems component testing and are applicable to automotive gas turbine testing. These probes are used to determine component or system performance from the measurement of gas temperature as well as total and static pressure, and flow direction. Detailed drawings of the sensors are presented along with experimental data covering the flow characteriatics over the range of intended use. 


\section{INTRODUCTION}

Automotive gas turbine testing requires small probes which measure temperature, pressure, and flow direction to help establish engine performance. Probes are avaliable to measure a single or a combination of these parameters. Furthermore, probes can be used in a fixed position at their measuring station or they can be actuated to rotate and/or translate to various positions. Compromises must be made in choosing any particular type of probe and the method in which it is applied. Some considerations involved are cost, size, accuracy, sensitivity, aerodynamic loading, vibration, and Installation problems. Before application, the probes limits and characteristics must be established. This present report described varịous miniature probes along with their flow characteristics, thus providing a prospective user with information to choose a given probe and interpret the test data it acquires.

\section{DESCRIPTION OF PROBES}

WEDGE-TYPE COMBINATION PROBE - Figure 1 presents the head detail of a wedge-type combination probe. This probe is a modification of the probe presented in (1).* The probe head consists of a $60^{\circ}$ Included angle blunted wedge with flow direction sensing orifices located on the wedge surface. Projecting upstream from the wedge are an internally beveled total-pressure tube and a tubular shlelded thermocouple. This sensing head assembly fits into a $\frac{1}{4}$ inch $\left(.64 \mathrm{~cm}\right.$ ) diameter support tube (not shown) with the centerline axis of the $\frac{1}{4}$ Inch $(.64 \mathrm{~cm})$ tube passing along the blunt leading edge of the wedge. The probe head is small enough to fall within the projected cross-sectional area of the support, thus, the probe can be inserted into a test region through a $\frac{1}{4}$ inch $(.64 \mathrm{~cm})$ diameter hole.

\footnotetext{
* Numbers in parenthesis designate References at end of paper.
} 
TUBE-TYPE COMBINATION PROBE - Figure 2 presents the head detail of a tube-type combination probe. The probe head consists of a 3 tube bundle containing a center position total pressure tube with two $45^{\circ}$ angled inlet tubes on elther side for sensing flow direction. An unshielded 36 gage wire thermocouple lies above and parallel to the total pressure tube to complete the temperature, pressure, and flow angle comblnation sensor. This sensing head assembly fits into a $3 / 16$ inch $(.48 \mathrm{~cm}$ ) diameter support tube (not shown) in such a manner that it falls within the projected cross-sectional area of the support tube.

TEMPERATURE PROBES - FIgure 3 shows a simple bare-wire crossflow thermocouple probe design using a $1 / 8$ inch $(.32 \mathrm{~cm})$ diameter cylindrical support. A related type of probe has been previously reported in $(2,3$, and 4).

Figure 4 shows a semi-shielded high-recovery probe. This probe uses a $3 / 32$ inch $(.24 \mathrm{~cm})$ diameter support tube with a notched end which places the crossflow thermocouple in the stagnation region of the notched end. Other probes of this type have been described in $(3,4$, and 5$)$.

Sheath and wire materials for these two thermocouple probes (figs. 3 and 4) may be chosen to meet the requirements for cold-flow component tests as well as high temperature testing of the complete engine assembly.

\section{PROBE CHARACTERISTICS}

Characterlst1cs of the probes were determined for flow conditions where the probe is alined with the flow as well as for the case where the probe is unalined with the flow. The probes can therefore be used with actuators or in fixed position. Flow orientation nomenclature is presented in figure 5. TEMPERATURE MEASUREMENTS - In using thermocouple probes, it is conventent to correct for an aerodynamic recovery error by using a recoverycorrection factor $\Delta$. 


$$
\Delta:=\frac{T_{t}-T_{\text {ind }}}{T_{t}}
$$

where $T_{t}$ is total temperature and $T_{\text {ind }}$ is the indicated thermocouple junction temperature. A11 temperatures are absolute. In an application in which the function has responded to the aerodynamic flow, and where conductive and radiative heat exchange is not present, the quantity $\mathrm{T}_{\text {ind }}$ is equal to the adiabatic function temperature, and $T_{t}$ can be calculated from the Indicated function temperature and the value of $\Delta$.

$$
T_{t}=\frac{T_{\text {ind }}}{1-\Delta}
$$

and since $\Delta \ll 1$

$$
T_{t} \approx T_{\text {ind }}(1+\Delta)
$$

The recovery-correction factor of a thermocouple probe, in alined flow, varies primarily with stream Mach number, with a secondary effect of stream pressure. The recovery-correction factor for alined flow, at 1 atmosphere $\left(1 \times 10^{5} \mathrm{~N} / \mathrm{m}^{2}\right.$ ) stream total pressure, will be termed the reference recoverycorrection factor " $\Delta_{0}$.

The variation of $\Delta_{0}$ with Mach number for the probes reported herein is presented in figure 6. The curves presented here represent the average calibration for several probes. In general, deviations of \pm 10 percent of the average given value for $\Delta_{0}$ can occur due to material and probe manufacturing variances. For maximum accuracy, probes should be individually calibrated before and periodically during application. Shielded probes are more inclined to change calibration during usage because of their higher susceptibility to flow passage area change from stream particles and thermocouple "grounding" to the close proximity shields. The combination wedge $\Delta_{0}$ curve is higher valued than that usually expected for a shielded probe. The reason 
is that its shield geometry allows stralght-through flow with only a small amount of stagnation at the wire bend.

The varfation of the recovery-correction factor with pressure, for alined flow, is shown in figure 7. Conductive heat exchange from the support and/or shield is probably the largest contributing factor to this effect, w1th the greater sensitivity felt in the low pressure (lower density) regions. As seen in the figure, the high-recovery shielded probe is effected to a greater extent by this condition.

Variation of recovery-correction factor-ratio with yaw angle (see fig. 5 for flow angle orientation) is presented in figure 8 . It is seen from these curves that the variation of $\Delta$ with yaw for the combination wedge, combination, tube, and high recovery probe is only slight with small angles of yaw $\left( \pm 10^{\circ}\right)$. The crossflow design, however, is not only highly sensitive to change in $\Delta$ with change in yaw (up to 10 percent change at $10^{\circ}$ ) but is also subject to a wider variation with Mach number than the other probes. Thus, the data is presented as a cross-hatched area. The use of this probe should be restricted to applications where such uncertainties in $\Delta$ with flow angle are not significant. No data is presented for deviation from zero pitch angle since in the majority of applications the probes can be inserted into a test region, so that, the variation in flow in one plane (pitch) is negligible (say less than $5^{\circ}$ ) and only the variation in the yaw plane must be accounted for. An approximation of radiation losses for the crossflow and high-recovery thermocouple probes (which are applicable to the hot sections of the engines) may be obtained from information found in (2 and 4) where:

$$
\text { Radiation correction, }{ }^{\circ} \mathrm{R} \approx \frac{\mathrm{C} \varepsilon_{\mathrm{W}}}{\sqrt{\mathrm{Mp}_{\mathrm{p}}}}\left(\frac{\mathrm{T}_{\text {ind }}}{1000}\right)^{3.82}\left[\mathrm{I}-\left(\frac{\mathrm{T}_{\mathrm{d}}}{\mathrm{T}_{\text {ind }}}\right)^{4}\right]
$$

where $C$ is the radiation constant for a particular probe, $\varepsilon_{w}$ is total hemispherical emittance of the thermocouple wire, $M$ is stream Mach number, $P$ 
Is stream static pressure in atmospheres, $T_{\text {ind }}$ is indicated thermocouple temperature ${ }^{\circ}$, and $T_{d}$ is enclosure duct temperature ${ }^{\circ}$. The "c" values for the two probes are:

$$
\begin{aligned}
& \text { bare-wire crossflow }=3.8 \\
& \text { high recovery probe }=5.2
\end{aligned}
$$

Valuee of emittance for type $\mathrm{K}$ thermocouples may be estimated from (6) where the values range from 0.2 to 0.3 for a clean bright wire and 0.7 to 0.9 for a highly oxidized wire. Enittances of 0.7 to 0.8 were found for bare type $\mathrm{K}$ thermocouples (4) run for $\frac{1}{2}$ to $I$ hour in the exhaust gas of a gasoleneair combustor.

YAW ANGLE MEASUREMENT - Although the combination probes presented herein are primarily intended to be used with an actuator that supplies linear and/or rotational positioning, they may be used to a limited extent in a flxed position. The value for the yaw angle $\beta$ can be obtained from probe measurables using figure 9, where $p_{t, \text { ind }}$ is indicated total pressure and $P_{1}$ and $P_{2}$ are the pressures measured by each of the directional sensing taps. As with the thermocouple sensors, deviations of \pm 10 percent of the average values of figure 9 can occur due to manufacturing variances; so, for maximum accuracy, individual probe calibrations are required.

TOTAL PRESSURE MEASUREMENT - The variation in indicated total pressure with yaw angle for the two combination probes used in a flxed position is presented in figure 10, where $p_{t}$ is total pressure. Thts figure is used to obtain stream total pressure from probe measurables after determining yaw angle through use of figure 9. Additional flow-angle characteristics of several miniature total-pressure tubes are given in (7).

STATIC PRESSURE MEASUREMENT - For accurate static-pressure measurement it is desirable that the sensing element be many diameters upstream from the probe support, as in the Prandt1-type tube. Because the probes must usually 
pass through a small hole and have the sensing elements near the centerline of rotation, most small combination probes do not include the ability to measure stream static pressure. However, if it is required that the combination probes have the ability to measure the static pressure, one of the angle-sensing holes (or the average pressure of the two holes) is normally used as an Indication of this pressure (1). Of the two combination probes presented here, the wedge type is preferred for static pressure because its angle ports indicate a pressure much closer to stream static pressure than the tube type. The uncertainty in static pressure resulting from using such a techntque is due to probe blockage and the variation in blockage as the probe traverses the passage. An alternate approach to the measurement is to use static pressure obtained from wall static pressure taps along with the calculated values obtained from other measurables.

\section{PROBE. ACTUATOR SYSTEM}

A typical probe actuator system is use at the Lewis Research Center is shown in figure 11. The actuator is capable of both 1inear and angular motion. Typical ranges of motion are 6 inches $(15 \mathrm{~cm})$ linear travel and \pm 90 degrees rotational movement. A block diagram of the complete actuation system is shown in figure 12 .

The position command for linear travel may be manually operated or computer programmed to stop at pre-determined points. Linear positioning accuracy can be acquired to about 0.15 percent of full travel.

The flow angle sensing ports of the probe are connected to a differential pressure transducer which converts pressure unbalance (misalinement with flow) to an electrical signal. This electrical unbalance signals the rotational system to automatically bring the probe back to zero flow angle. Sensitivity of the flow angle system varies approximately linearly with 
pressure and with the square of the flow velocity. The overall flow angle measurement uncertainty for nomina11y mid-range subsonic Mach number flows, at one atmosphere pressure, is about one degree.

\section{SUMMARY}

Design details, general characteristics, and discussions of applications and Ilmits for several miniature fluid flow probes were presented. The probes which measure temperature, pressure and flow direction can be used in a fixed position or in an actuator system. Information on a typical probe actuator system was also presented. 
REFERENCES

1. G. E. Glawe, L. N. Krause, and T. J. Dudzinski, "A Sma11 Combination Sensing Probe for Measurement of Temperature, Pressure, and Flow Direction". NASA TN D-4816, October 1968.

2. M. D. Scadron and I. Warshawsky, "Experimental Determination of Time Constants and Nusselt Numbers for Bare-Wire Thermocouples in HighVelocity Air Streams and Analytic Approximation of Conduction and Radiation Errors". NACA TN 2599, January 1952.

3. T. M. Stickney, "Recovery and Time-Response Characteristics of Six Thermocouple Probes in Subsonic and Supersonic Flow". NACA TN 3455, July 1955.

4. G. E. Glawe, F. S. Simmons, and T. M. Stickney, "Radiation and Recovery Corrections and Time Constants of Several Chromel-Alumel Thermocouple Probes In High-Temperature, High-Velocity Gas Streams." NACA TN 3766, October 1956 .

5. S. J. Markowski and E. M. Moffatt, "Components Involving Fluid Flow". SAE Quarterly Transactions, Vol. 2, Jan. 1948, pp. 104-116.

6. W. D. Harvey, L. E. Forrest, and F. L. Clark; "Measurements of Total Hemispherical Emittance for Chromel and for Alumel Wires". NASA TMX-2359, September 1971.

7. T. J. Dudzinski and I. N. Krause, "Effect of Inlet Geometry on FlowAngle Characteristics of Miniature Tota1-Pressure Tubes". NASA TN D-6406, Ju1y 1971. 


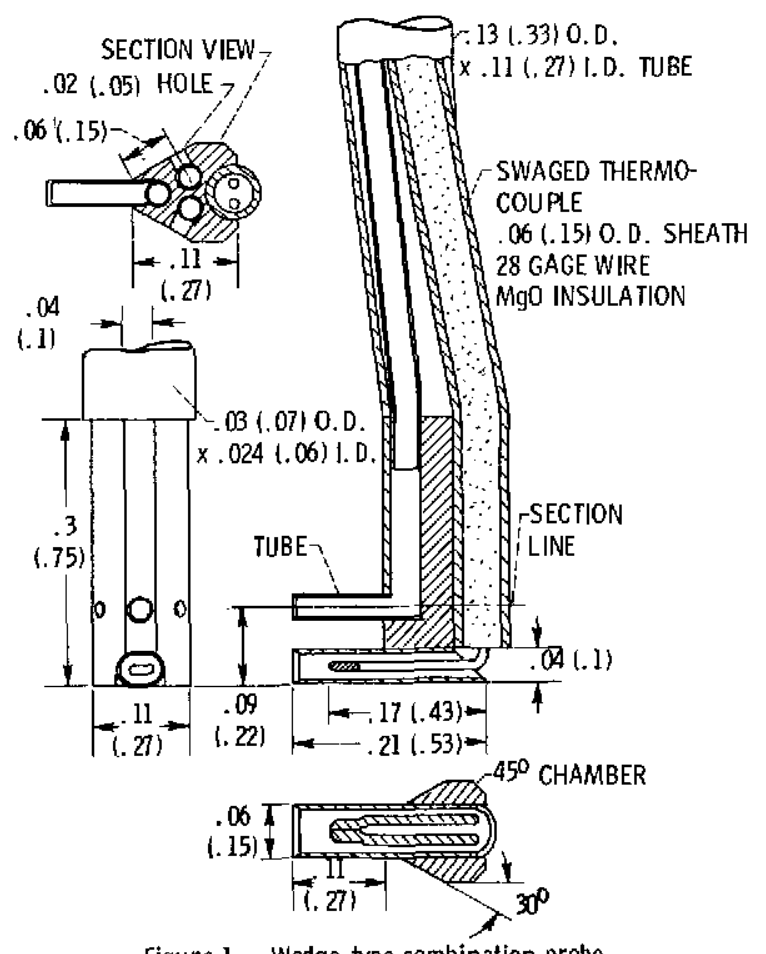

Figure 1, - Wedge-type combination probe.

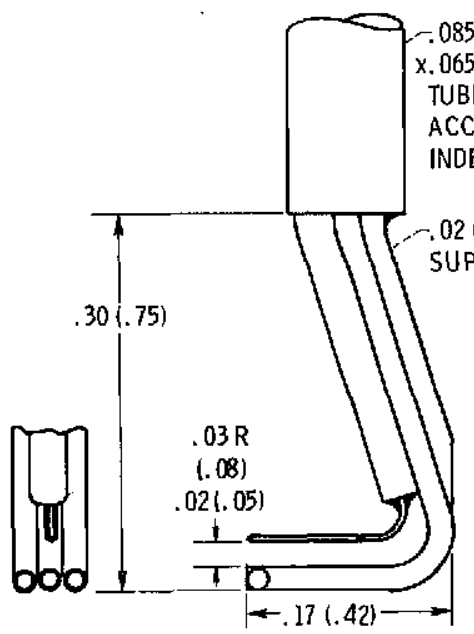

WELD JUNCTION REMOVE EXCESS BEAD--

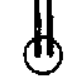

SWAGED TC ASSEMBLY $.03(.08)$ 0.D. SHEATH

$.02(.05) 0.0$.

$\times .015(.04)$ I.D. TUBES

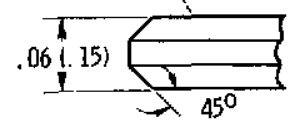

36 GAGE WIRE

MgO INSULATION

Figure 2. - Tube-type combination probe. 


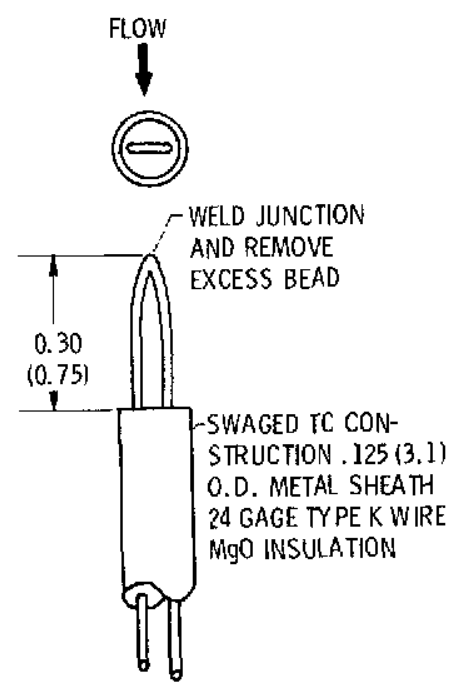

Figure 3. - Bare wire - crossflow thermocouple.

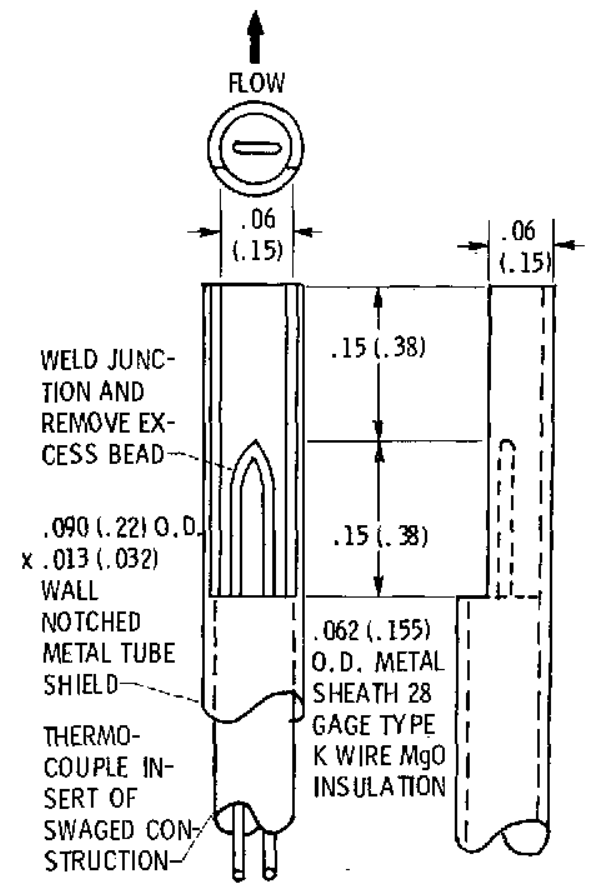

Figure 4. - High recovery thermocouple.

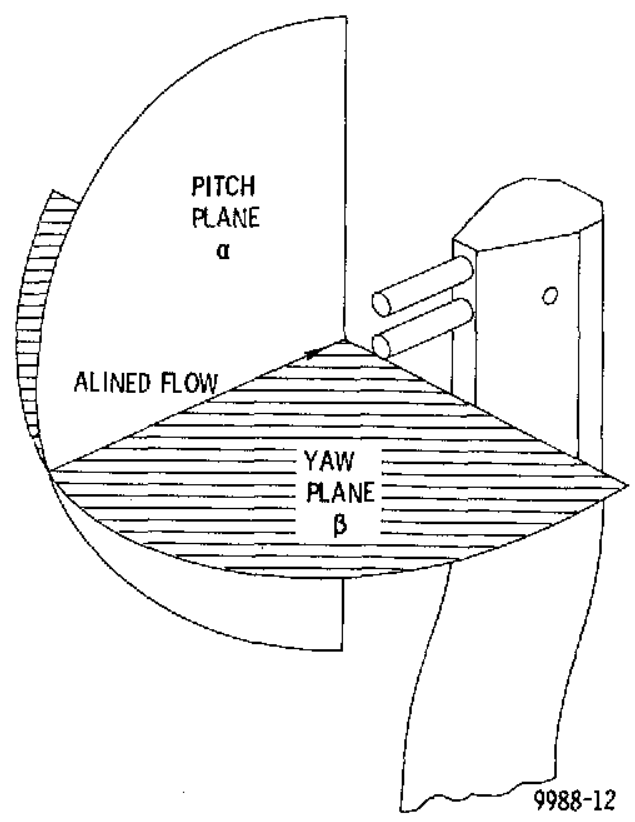

Figure 5. - Flow orientation nomenclature. 


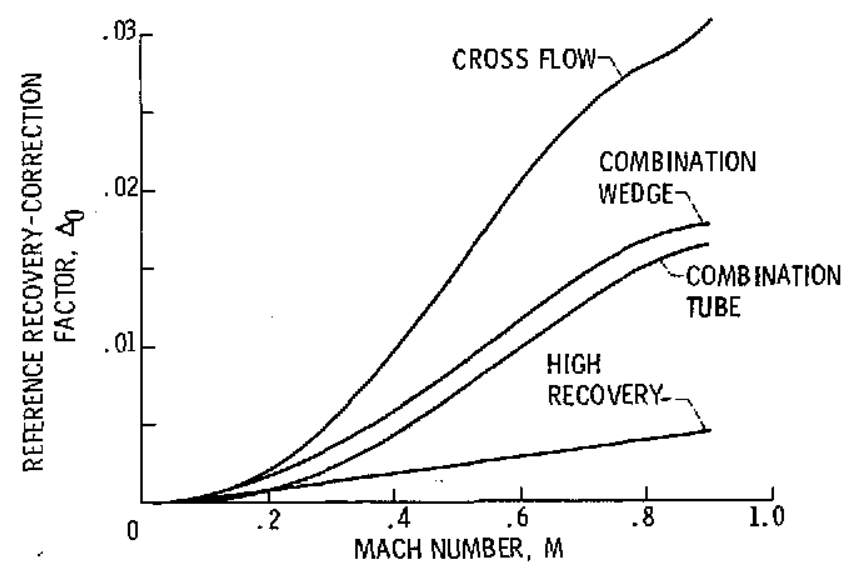

Figure 6. - Variation of reference recovery-correction factor with Mach number. $\Delta_{0}$ is the recovery-correction factor at a total pressure of 1 atmosphere $\left(I \times 10^{5} \mathrm{~N} / \mathrm{m}^{2}\right)$. Alined flow.

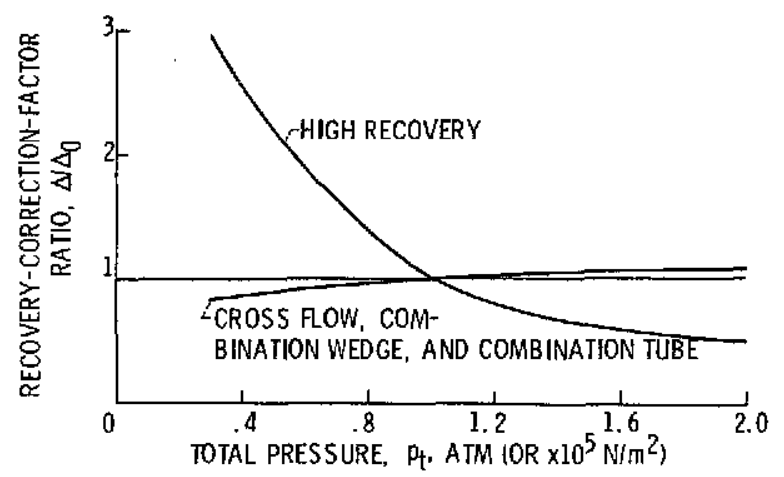

Figure 7. - Variation of recovery-correction-factor ratio with pressure. Alined flow. $0.6 \leq M \leq 0.9$.

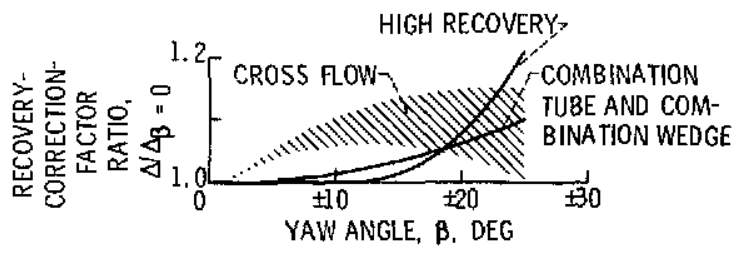

Figure 8. - Variation of recoverycorrection-factor ratio with yaw angle: $0.3 \leq M \leq 0.9$. 


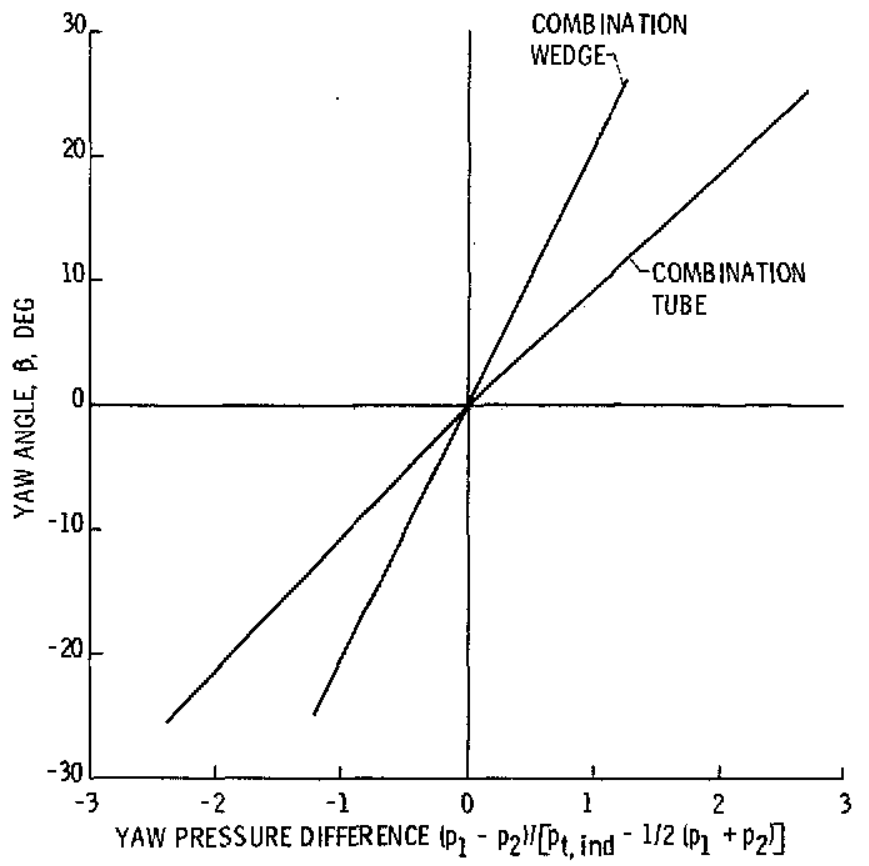

Figure 9. - Variation in yaw pressure difference with yaw angle. $0.3 \leq M \leq 0.9$.

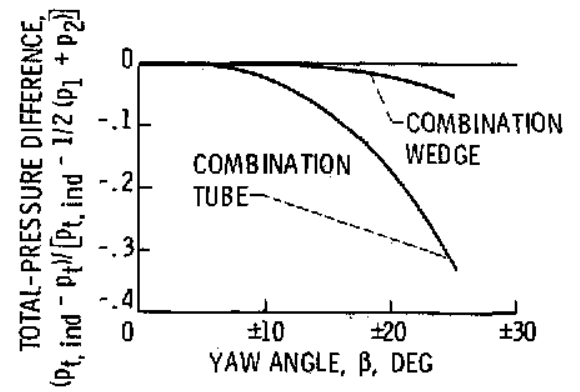

Figure 10. - Variation in total-pressure difference with yaw angle. $0.3 \leq M \leq 0.9$. 


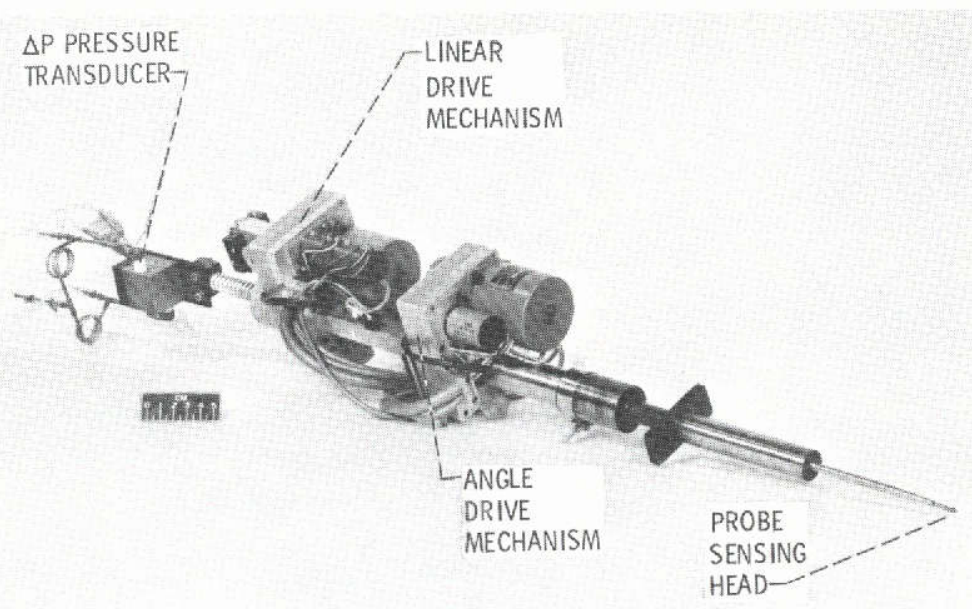

Figure 11. - Actuator, $\triangle \mathrm{P}$ pressure transducer, and probe assembly.

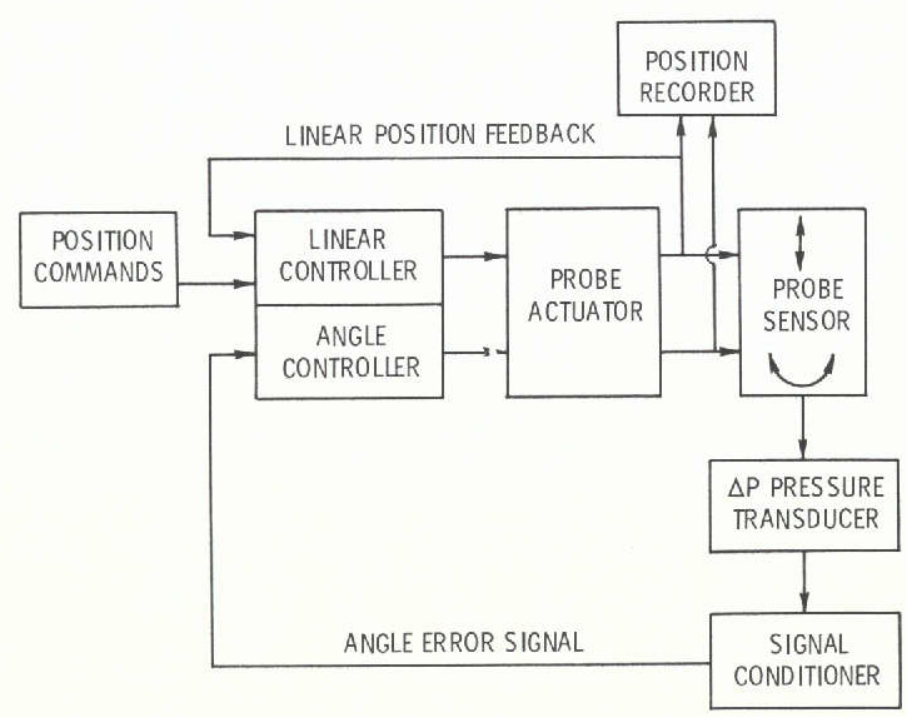

Figure 12. - Probe actuation system. 